\title{
El elusivo paso por las escuelas: alumnos en el Estado de México a mediados del siglo XIX
}

\author{
The elusive time in schools: students of the Mexico state during the mid- \\ nineteenth century
}
A ilusória passagem pelas escolhas: alunos no Estado do México em meados do século XIX

Recepción: 20/01/2020

Evaluación:29/03/2020

Aceptación: 01/04/2020

Artículo de Investigación - Reflexión

https://doi.org/10.19053/01227238.10896

José Bustamante Vismara ${ }^{1}$

Universidad Nacional de Mar del Plata, Argentina

\section{RESUMEN}

Objetivo: ¿Qué es posible conocer acerca de las actividades cotidianas de los escolares de mediados del siglo XIX? ¿En qué sentidos atender a sus actividades puede servir para comprender aspectos de la sociedad hispanoamericana? Método: El trabajo recupera experiencias vividas en ámbitos educativos del valle de Toluca en el Estado de México a mediados del siglo XIX atendiendo, fundamentalmente, a sus alumnos. Un punto de intersección entre la historia de la educación y la de la infancia. Estrategias: En el análisis se caracterizarán pautas ligadas a sus asistencias, vivencias cotidianas y castigos. Con un análisis cualitativo se recuperan testimonios de distintos archivos, en los que el privilegio de la perspectiva es advertido desde fuentes recuperadas en repositorios históricos municipales de la región de Toluca, México. Originalidad: A partir de la tarea ha sido posible atender a especificidades que difícilmente hubieran podido reconocerse desde miradas más generales y se concluye que la esquiva visibilidad de estos alumnos responde a aspectos propios de la sociedad en el período.

Palabras clave: México; Estado de México; Educación; Siglo XIX; Alumnos - Vida escolar.

$1 \quad$ Doctor en Historia. Docente e investigador del Departamento de Historia - Centro de Estudios Históricos de la Universidad Nacional de Mar del Plata. Investigador adjunto del CONICET, Argentina, correo electrónico: jovisma@hotmail.com 


\section{ABSTRACT}

What is it possible to know about the daily activities of schoolchildren from the mid-19th century? To what extend knowing their daily activities can serve to understand aspects of Hispanic American society?

The work recovers experiences lived in educational areas of the Toluca Valle in the State of Mexico in the mid-nineteenth century, paying attention to students' activities. There is a point of intersection between the history of education and childhood. The analysis will characterize patterns linked to their assistance, daily experiences, and punishments. With a qualitative analysis, testimonies from different files are collected, in which the privilege of the perspective is noticed from sources recovered in municipal historical repositories. From them it has been possible to attend to specificities that could hardly have been recognized from a more general perspective. The purpose is to carry out a social and cultural history of education in which students are the focus of attention. What was analyzed focuses on the Toluca region, but the perspective suggests that the elusive visibility of these students responds to aspects of society in this period.

Keywords: Mexico, Mexico state; education; $19^{\text {th }}$ century; students; school life.

\section{RESUMO}

O que é possível conhecer acerca das atividades cotidianas dos estudantes de meados do século XIX? Em quais sentidos atender a suas atividades pode servir para compreender aspectos da sociedade hispano-americana? O trabalho recupera experiências vividas em contextos educacionais do vale de Toluca, no Estado do México, em meados do século XIX, atendendo, fundamentalmente, a seus alunos. Um ponto de intersecção entre a história da educação e da infância. Nesta análise se caracterizam pautas ligadas a suas assistências, vivências cotidianas e castigos. Com uma análise qualitativa se recuperam testemunhos de diferentes

arquivos, em que o privilégio da perspectiva é percebido a partir de fontes recuperadas em arquivos históricos municipais. A partir deles, foi possível atender a especificidades que dificilmente puderam reconhecer-se a partir de perspectivas mais gerais. $\mathrm{O}$ propósito é levar adiante uma história social e cultural da educação em que os alunos sejam o foco da atenção. A análise concentra-se na região de Toluca, porém a perspectiva sugere que a pouca visibilidade destes alunos responde a aspectos próprios da sociedade no período.

Palavras-chave: México; Estado do México; educação; século XIX; alunos, vida escolar. 


\section{INTRODUCCIÓN}

pasé lista y solo diez niños son los que hay, por cuya razón les tomé su lección y los mandé para su casa. Esto parece juego de niños, pues el que quiere venir viene y el que no nó y á la hora que quiere venir; sin embargo de los castigos que les impongo. ${ }^{2}$

Felipe Gutiérrez fue maestro en Capulhuac, Estado de México. El epígrafe de este texto es un fragmento del oficio que escribió hacia 1860, una ilustrativa referencia para observar los problemas que se articularán en este trabajo - castigos y asistencia - con el propósito de reconocer aspectos de la historia de los alumnos.

En los trabajos de historia de la educación los escolares tienen un lugar mucho menos destacado que el ameritado por la temática. Aunque son un sugestivo actor y resulta clave conocerlos para ofrecer una descripción de los establecimientos educativos, es poco lo que se sabe sobre ellos. Este presupuesto podría afirmarse para distintos períodos y regiones, pero lo sabido sobre los asistentes a escuelas públicas de mediados del siglo XIX en Hispanoamérica es, por caracterizarlo de algún modo, escueto. En las indagaciones sobre el campo tienen un papel mucho más destacado los análisis sobre políticas educativas, reformas curriculares, formación de educadores o métodos pedagógicos. Ello responde tanto a intereses historiográficos, como a las dificultades de acceder a fuentes sobre estos actores. Es por esto que el oficio de Felipe Gutiérrez resulta tan sugestivo. Allí se anuncian asuntos sobre los que se trabajará y que permiten cierto acercamiento al elusivo universo social que aquí interesa reconocer.

Con el propósito de avanzar sobre la cuestión, este trabajo se centra en procesos educativos sucedidos en escuelas públicas del valle de Toluca a mediados del siglo XIX. La perspectiva es fundamentada a partir de testimonios recogidos en distintos archivos, pero el tono y las vivencias resultan inteligibles a partir de fuentes recuperadas en archivos históricos municipales. Es decir, los documentos del Archivo General de la Nación y del Archivo del Estado de México han sido importantes, pero el grueso de la información que ha resultado clave para esta perspectiva ha sido recuperado de repositorios municipales ${ }^{3}$. A partir de ellos ha sido posible atender a especificidades que difícilmente hubieran podido reconocerse desde miradas más generales.

¿Qué sugieren las experiencias educativas de estos escolares sobre la sociedad mexicana decimonónica? ¿Los vínculos intergeneracionales se alteraron con el

2 Estado de México, 8 mayo 1858, sección Educación, fondo Educación, Archivo Histórico Municipal de Capulhuac (AHMC). En la cita de fuentes se ha respetado la ortografía de los documentos transcriptos. Como puede advertirse en este caso, el modernizar o corregir hubiera alterado el tono de los testimonios trabajados.

3 La documentación relevante para el trabajo ha sido obtenida del Archivo General de la Nación (AGN), del Archivo Histórico del Estado de México (AHEM) y, sobre todo, de los archivos históricos municipales de Tenango del Valle (AHMTV), Metepec (AHMM), Zinacantepec (AHMZ), Ocoyoacac (AHMO), Almoloya de Juárez (AHMAJ), Capulhuac (AHMCP), San Antonio la Isla (AHMSAI) y Calimaya (AHMCM). 
republicanismo y la organización política postindependiente? ¿Qué características tuvieron las infancias mexicanas del período? Sin dudas, los interrogantes enumerados son más amplios de lo que este acercamiento aspira a lograr, se trata de cuestiones que orientan el marco en que se inserta el interés del trabajo y que, fundamentalmente, se aboca a tratar de reconocer aspectos sobre los escolares del período.

La propuesta dialoga con trabajos de, al menos, dos conjuntos temáticos: la historia de la educación y la historia de la infancia. Los estudios sobre lo educativo y la escolarización a lo largo del siglo XIX mexicano han tenido un nutrido desarrollo. Al igual que en otras historiografías, a lo largo de las primeras décadas del siglo XX los acercamientos estuvieron ligados a pautas institucionales y prescriptivas, para luego - hacia 1970 - comenzar a atender procesos sociales, políticos y económicos en diálogo con lo educativo ${ }^{4}$. Mientras que entre fines del siglo XX y principios del XXI se incrementaron los análisis sobre algunos espacios regionales, así como se desarrollaron investigaciones que pueden ligarse a la historia cultural ${ }^{5}$. En diálogo con estos análisis, desde la historia de la infancia se han realizado trabajos sugestivos ${ }^{6}$. Aquí la propuesta se nutre de estas investigaciones, pero también se distingue de ellas en la medida que se acota a un determinado contexto institucional, a la presencia del maestro - y no del padre o la madre - y al compartir horas con otros pares. En suma, aquí se trata de darle sentido a una historia del elusivo paso de los alumnos por estos ámbitos institucionales. Lógicamente, tal omisión no fue exclusiva de este ámbito regional, sino que fue una característica compartida por diversas regiones hispanoamericanas en el siglo XIX.

\section{Escuelas del valle de Toluca}

El desarrollo de escuelas públicas en el México postindependiente se articuló al impulso republicano. Un orden político afirmado en la soberanía popular suponía ciudadanos con capacidad para intervenir en su condición de electores o funcionarios. Así, la educación de las jóvenes generaciones se erigió como un

$4 \quad$ Desarrollos sobre la temática pueden verse en Anne Staples, "Recent Trends in the Historiography of Mexican Education”, Paedagogica Historica 36, n. 3 (2000); Alicia Civera, "Alcances y retos de la historiografía sobre la escuela de los campos en América Latina (siglos XIX y XX)", Cuadernos de Historia, n. $^{\circ} 34$ (2011).

5 Entre otros trabajos, puede aludirse a Anne Staples, Recuento de una batalla inconclusa: la educación mexicana de Iturbide a Juárez (México, D.F. : El Colegio de México, 2005); María Adelina Arredondo López, En la senda de la modernidad: un siglo de educación en Chihuahua, 1767-1867 (Zamora, Michoacán, México: El Colegio de Michoacán, 2011); Eugenia Roldán Vera, The British Book Trade and Spanish American Independence: Education and Knowledge Transmission in Transcontinental Perspective (Aldershot, Hants, England: Ashgate, 2003); Mílada Bazant de Saldaña, En busca de la modernidad: procesos educativos en el Estado de México, 1873-1912 (Zinacantepec - Zamora, México: El Colegio Mexiquense - El Colegio de Michoacán, 2002); Carlos Escalante Fernández, Mazahuas, campesinos y maestros. Prácticas de escritura, tierras y escuelas en la historia de Jacotitlán, Estado de México (1879-1940) (Zinacantepec, México: El Colegio Mexiquense, 2014).

6 Con miradas generales sobre la región hispanoamericana, pueden verse: Pablo Rodríguez Jiménez y María Emma Mannarelli, coords., Historia de la infancia en América Latina (Bogotá: Universidad Externado de Colombia, 2007); Susana Sosenski y Elena Jackson Albarrán, coords., Nuevas miradas a la historia de la infancia en América Latina: entre prácticas y representaciones (México: Universidad Nacional Autónoma de México - Instituto de Investigaciones Históricas, 2012); Cecilia Rincón Verdugo, "Historiografía sobre las significaciones imaginarias de infancia en la cultura de Occidente”, Revista Historia de la Educación Latinoamericana, vol. 20, n. $^{\circ} 31(2018)$. 
condicionante para la viabilidad y sustentabilidad del orden. Y si bien cada una de las instancias de gobierno puso a la resolución de los problemas educativos entre sus objetivos, la experiencia comprobaría que era un desafío colmado de dificultades?.

En el Estado de México la administración de las escuelas elementales fue dejada en manos de los ayuntamientos. Se ha mostrado que tras el proceso de independencia hubo una reorganización y jerarquización que distinguió a determinados ámbitos territoriales en detrimento de otros; previsiblemente, la capital del Estado recibió más recursos que las cabeceras de ayuntamiento, y estas más que los pueblos. La disposición no habría llamado la atención si no hubiera sido contrastada con el amplio horizonte educativo que se había desenvuelto a fines del siglo XVIII en los pueblos de indios ${ }^{8}$.

Con el correr de la década de 1820, las escuelas elementales quedaron bajo la supervisión de juntas ligadas a los municipios. El proyecto de ley sobre Instrucción Pública de 1833 afirmaba: "Creemos haber encontrado un antemural seguro contra el despotismo en la institución de juntas populares que vigilen sobre la instrucción pública, y si la tiranía llegara a apoderarse del Estado, este sería el último asilo de los hombres libres"9. Tal presupuesto afirmado por legisladores estatales lejos estuvo de ser linealmente replicado por los ayuntamientos. Sus actuaciones variaron al compás de los ritmos políticos, de los intereses de quienes las integraban, de las posibilidades de financiamiento, entre otras particularidades ${ }^{10}$. Sería a fines del siglo XIX cuando se produciría cierta centralización y una creciente intervención del ejecutivo estatal en el asunto ${ }^{11}$. Entonces, las especificidades propias de cada uno de los ayuntamientos comenzaron a ser diluidas.

Las siguientes páginas tratan, precisamente, del período en que la administración de las escuelas públicas estuvo bajo la gestión de juntas articuladas por los ayuntamientos. Juntas colegiadas, integradas por alguna autoridad política del municipio, un sacerdote y un par de vecinos. Ellos, en diálogo con las autoridades estatales, se encargaban de las escuelas referidas.

El valle de Toluca, hacia mediados del siglo XIX, tenía ciento veinte mil habitantes. La mayor parte de la población estaba radicada en alguno de los casi noventa pueblos de menos de mil habitantes. Los asentamientos de más de dos mil pobladores fueron nueve, mientras que la ciudad de Toluca alcanzaba los ocho mil ochocientos dos pobladores ${ }^{12}$. En el valle se hablaba otomí, mazahua,

$7 \quad$ Staples, Recuento de una batalla.

8 Sobre el período tardocolonial, es clave el panorama presentado por Dorothy Tanck de Estrada, Pueblos de indios y educación en el México colonial, 1750-1821 (México, D.F.: El Colegio de México - Centro de Estudios Históricos, 1999). Y acerca de las transformaciones sucedidas a principios del siglo XIX puede verse: José Bustamante Vismara, "Un proceso de reorganización territorial advertido desde las escuelas elementales: el valle de Toluca entre fines del siglo XVIII y principios del siglo XIX", Tzintzun. Revista de Estudios Históricos n. ${ }^{\circ} 61$ (2015).

9 1833, Expediente 56, tomo 71, Cuarta legislatura, Biblioteca del Congreso del Estado de México "José María Luis Mora".

10 José Bustamante Vismara, Escuelas en tiempos de cambio: política, maestros y finanzas en el valle de Toluca durante la primera mitad del siglo XIX (México, D.F.: El Colegio de México, Centro de Estudios Históricos, 2014).

11 Bazant de Saldaña, En busca de la modernidad.

12 Los datos corresponden a registros de 1865 y han sido elaborados a partir de: Expediente 64, caja 17, Instrucción Pública y Bellas 
matlatzinca y náhuatl, además del español; pero en las escuelas solo este último es referido.

Es difícil precisar el número de establecimientos que efectivamente funcionaron en el período postindependiente. Aunque hubo conteos que indicaron un número determinado de establecimientos, la irregularidad fue general. Y esta intermitencia fue solo parcialmente morigerada en las escuelas de las cabeceras de los ayuntamientos. En suma, funcionaron de cinco a quince escuelas en cada una de las jurisdicciones municipales, pero se trata de una estimación que solo permite dar cuenta de una tendencia. Es un período en el que autoridades, maestros y alumnos concurrieron con irregularidades que le dan sentido al interrogante de ¿quiénes querían y efectivamente alentaban estas instituciones? ¿Los padres o madres apoyaban tales iniciativas? Lejos de haber un generalizado sostén, no faltaron expresiones como las referidas desde Taltizapan, Capulhuac, en abril de 1858. El auxiliar consideraba a los padres de los alumnos como unos "ingratos". Y precisaba: "se burlan a cada paso de las muchas providencias que U. toma para hacer cumplir con mandar diariamente a sus hijos a la escuela"13. No fue inusual la caracterización. La escolarización estaba lejos de ser aceptada como un lugar indispensable para la formación y preparación de los jóvenes. Incluso demandaba eventuales gastos para los padres, así como - se tratará más adelante - un potencial obstáculo para las tareas agrícolas o domésticas en las que niños y niñas eran involucrados.

La estructura material de estos establecimientos ha sido caracterizada por su fragilidad y pobreza ${ }^{14}$. Por ser los inventarios un documento indispensable para el momento de inicio o cese de un preceptor al frente de una escuela, se constituyen en una vía conveniente para reconocer sus características. $\mathrm{Al}$ recibir el establecimiento afirmaban la existencia de determinados bienes de los cuales pasaban a ser responsables. Los inventarios, entonces, se constituían en un engranaje de referencia en la rotación de educadores. Circulación que, cabe recordarlo, fue bastante frecuente.

En la corriente parquedad de aquellos listados de útiles y enseres, hay un testimonio que puede resultar sugestivo para la perspectiva que aquí se desarrolla, dado que en este se apuntan detalles sobre lo que los alumnos habrían hecho en el aula mientras se encontraban sin su maestro. Se trata del inventario que, en abril de 1828, redactó un maestro llamado José María de Leguizamón:

Lista que expresa los aperos de la Escuela Nacional de efte Pueblo que fué a cargo del C. José María de Leguizamón, hafta hoy 30 de Abril del presente año de 1828. $Y$ es como sigue:

Una Sta. Cruz con la imagen de N.S.I. pintada en ella, ya exteriorada

Artes [segunda serie], Archivo General de la Nación (AGN).

1314 enero 1858, sección Educación, fondo Educación, Archivo Histórico Municipal de Capulhuac (AHMCP).

14 Bustamante Vismara, Escuelas en tiempos de cambio. 
Una imagen de la Purísima Concepción; con su marco dorado, su repison, y un bastidorsito con estaquitas para poner milagros q-e dio ó dedicó el Sor. Cura, para Patrona

Un marco exteriorado que es del Quadrito de Ntro. amo, el que sacan el dia de Corpus, que antes estaba en la Escuela y haora nose en poder de quien para dho. lienzo

Unas Gradas que estan puestas de firme cuya compocision, y alguna madera costeó el Sor. Cura

Unas tres Mesas de Escrivir, dos acaballetadas de dos naves, y una tendida tosca hecha de una plancha bruta

Unos Quatro Bancos de sentarse, tres movedisos, y no defirme puesto sobre un pozo, y embutido en la pared

Unas Quatro Pautas utiles, una de $2^{\stackrel{a}{ }}$, otra de $3^{\underline{a}}$, otra de $4^{\underline{a}}$ y la otra que tiene $5^{\underline{a}}$ y $6^{\underline{a}}$

Unos Veinte y un tinteros que encontré embutidos en las mesas, seis utiles, y quinze quebrados (quando me entregué de dha. Escuela y los que según me impusieron los niños, los quebraron entiempo de mis antecesores los individuos Santiago Plata, Luis Plata, Quirino Carrasco, Jose Justo Rodriguez, y otros: que quando los dejaban solos se ponían a colarlos como huevos)

Un toayero

Un encerado para la ventana cuyo aforro o genero costeó el Sor. Cura

Un cuernito q-e destinaron p.a q.e bebieran agua

Una llave de la puerta que cae al Cementerio

Unas seis tablitas con sus Jesuses para los chiquitos.

Una mesita que havia para olla de la Agua estava tan devil q-e con el mismo peso de dha. Olla, se quebró, y quedó inservible de lo que le di parte al Sor. Cura. Asimismo la Llave de la puerta que cae para dentro del Curato, que recibí Yó, se la entregué luego, y es en poder del Sor. Cura. ${ }^{15}$

Esta enumeración retrata las condiciones materiales de un establecimiento e ilustra algunos rasgos de lo vivido en ellos por los alumnos. Las imágenes y los artefactos materiales ligados a lo religioso ocupaban un lugar destacado - en correspondencia al papel que dichos contenidos tenían en la enseñanza - , así como el apoyo del cura en sus adquisiciones. Este cumplió un papel clave en la gestión y el visado de las actividades de estas escuelas ${ }^{16}$. Entre los significativos datos que muestra el inventario citado, se alude a los tinteros estropeados durante el ejercicio de maestros anteriores por cuenta de que los alumnos "se ponían a colarlos como huevos", o a la mención de enseres para que bebieran agua.

La arquitectura de establecimientos referidos poco indica acerca de cómo eran vividas en forma cotidiana las clases. ¿Es posible conocer lo que allí sucedió? ¿En qué sentidos lo expresado en estos ámbitos puede enriquecer nuestra compresión de los procesos políticos del período? ¿Y acerca de la organización social? El

15 Expediente 2, caja 1, fondo Educación, Archivo Histórico Municipal de Metepec (AHMM). El oficio citado está firmado por el propio maestro (que en el texto alude a él en tercera persona) y no detalla a quién va dirigida la comunicación.

16 El asunto se relaciona con una constatación que cabe observar: los sacerdotes o párrocos tuvieron un papel destacado en la gestión de las escuelas públicas en el período, pero no estuvieron - como suele afirmarse-generalizadamente al frente de las clases. 
elusivo paso de los alumnos por las escuelas decimonónicas no permite atender a todos los aspectos que podrían ser sugestivos; pero algunos rasgos sí pueden ser recuperados. Y aunque se trata de facetas limitadas a ciertas temáticas, resultan un aporte para tratar de comprender y dimensionar aspectos que, desde perspectivas más generales, se diluirían.

\section{Azotes educativos}

En el marco de la crisis de la monarquía española, sucedida hacia 1810, comenzaron a tomar fuerza críticos discursos para con los castigos corporales y las penas aflictivas. Entre otras normas, en agosto de 1813 se expidió un decreto que estipulaba la "Prohibición de la correción de azotes en escuelas y colegios". Según esta, se debía

desterrar de entre los españoles de ambos mundos el castigo ó correcion de azotes, como contrario al pudor, á la decencia y á la dignidad de los que son ó nacen y se educan para ser hombres libres y ciudadanos de la noble y heróica nacion española. ${ }^{17}$

Y tras este diagnóstico se decretó la prohibición de corregir con azotes "en todas las enseñanzas, colegios, casas de correción y reclusión, y demás establecimientos de la monarquía"18. Que los cuerpos de los futuros ciudadanos no pudieran ser expuestos a penas que mancillen sus nombres daba sentido al mandato. No es este el marco para ahondar entre los claroscuros que articulan lo prescripto y las prácticas, basta referir que hacia mediados del siglo XIX los castigos corporales continuaban teniendo un lugar significativo en los establecimientos educativos. Y a través de estas experiencias resulta posible conocer algunas de las vivencias de los alumnos.

$\mathrm{Al}$ respecto resulta curioso lo sucedido en una de las escuelas de Toluca - la denominada Escuela Municipal de Guerrero- regenteada por Remigio Camacho y Otamendi. En un informe dirigido a la junta de instrucción pública, el preceptor mencionó varios inconvenientes ligados a la asistencia de sus alumnos, pero subrayó que cuando intentaba "darles palizas" a sus estudiantes, estos hacían tales movimientos o cabriolas que "en lugar de darlas naturalmente han salido lastimados" ${ }^{\prime 19}$. En consecuencia, el maestro castigaba a los niños con cierta dureza, pero por culpa de los propios alumnos... Para algunos padres ello era inaceptable, mas el maestro refutó tal objeción señalando que no faltaban progenitores que le encomendaron llevar adelante castigos a sus hijos, "como si el empleo de Preceptor me constituyera en verdugo de la Juventud" ${ }^{20}$.

17 Manuel Dublán, Mario Téllez G. y José López Fontes, La legislación mexicana de Manuel Dublán y José María Lozano [disco compacto, vol. 1] (México, D.F. - Toluca: Suprema Corte de Justicia de la Nación - El Colegio de México - Escuela Libre de Derecho - Tribunal Superior de Justicia del Estado de México, 2004).

18 Ibid.

19 Expediente 10, caja 2, sección 1, ramo 10, Archivo Histórico Municipal de Toluca (AHMT).

20 Ibíd. 
Unos años después, ya entrada la década de 1860 en Capulhuac, el maestro afirmaba que al iniciar sus actividades había hecho uso de la palmeta para castigar "con bastante moderación" a los niños; pero debió suprimir su empleo: "se levantó por algunos vecinos una grita terrible y para que en lo sucesivo no tuviera yo esta clase de molestia quise olvidar la aplicación de aquella" ${ }^{21}$.

Camilo Andrade fue un preceptor con una larga trayectoria en la región. En 1842, cuando iniciaba su carrera, se encontraba radicado en Metepec y fue criticado por los castigos que les habría aplicado a sus alumnos. En su respuesta señaló: "jamás he pensado en tratar a mis educandos con la aspereza que se me dice, pues sé corregir a los niños cuando me es ya indispensable, y si se les há aplicado castigos algo fuertes, há sido a niños que lo merecían"22. Años después, en 1858, en el ayuntamiento se recibió una nueva queja sobre sus castigos a los alumnos. Los vecinos del pueblo de San Francisco suscribieron una nota en la que manifestaban no estar dispuestos a tolerar con sus hijos tales apercibimientos ${ }^{23}$. El informe que se reprodujo en las actas de la junta del municipio indicó que el 7 de octubre los vecinos se expresaban:

encargandole también al Sr. Preceptor Camilo Andrade que evite [...] detención a las horas de salida, y que no les permita que salgan a comer en los magueyes por no ser ese un lugar a propósito para ello, y mas bien lo hagan dentro del mismo local para eximirlos de un mal funesto que puede ocasionarles esa costumbre. ${ }^{24}$

¿En qué estarían pensando estos padres? ¿Cuál era el "mal funesto" que se derivaría de almorzar en los magueyes? Una estela de dudas semejante asoma ante otra carta - del mismo año, pero sin fecha precisa - con la que también se criticó al preceptor Camilo Andrade. En esta se indicó que algunos de los miembros de la junta habrían justificado las inasistencias de los alumnos en virtud de unos castigos "muy penosos" que imponía el mencionado Andrade. No nos detallan cuáles habrían sido tales castigos, pero el preceptor se mantuvo en el cargo unos años más.

¿Era un buen educador el que no castigaba? ¿O lo era el que castigaba "poco"? En Almoloya la junta elogió el desempeño de un preceptor provisorio. En una carta que se le dirigía, tras aludir a los adelantos de los niños, se le recomendó que "continue con la misma eficacia y a cada niño le enseñe según conozca su capacidad, tratándolos con amor y con castigos leves a los que sea muy necesario aplicárselos" 25 .

212 de agosto de 1867, expediente sin número, sección educación, fondo Educación, Archivo Histórico Municipal de Capulhuac (AHMCP).

22 Expediente 17, caja 1, fondo Educación, Archivo Histórico Municipal de Metepec (AHMM).

23 Expediente 51, caja 2, fondo Educación, Archivo Histórico Municipal de Metepec (AHMM).

24 Ibid.

25 Expediente sin número, caja 19, Archivo Histórico Municipal de San Antonio la Isla (AHMSAI). 
Entre los distintos sesgos que presentan estos registros, el género de los alumnos no pasa desapercibido. ¿No hubo niñas castigadas? ¿O los testimonios sobre el asunto no llegaron a los escritorios de los ayuntamientos? Un testimonio acerca del asunto lo refirió la preceptora Elena Laura Muñoz, en agosto de 1859, quien regenteaba una "amiga" en los establecimientos de San Antonio y San Lucas. Estas escuelas eran usualmente dirigidas por mujeres y a ellas asistían niñas o niños pequeños. Y si bien estos establecimientos apenas eran visados por las juntas de los ayuntamientos y solo esporádicamente participaban de los exámenes públicos, Elena Muñoz elevó oficios con información sobre su institución. Una de las cartas remitidas a la junta de instrucción pública indica:

En la mañana de hoy há venido á esta escuela Da. Mónica Rocha, á entregarme a su hijo Cristobal, joven, que a mi entender pasa de la edad prescripta por las leyes para ser recibido como alumno; y tanto por esto, cuanto por que no hay castigo en el reglamento, que crea yo adecuado para aplicárselo en caso que lo merezca, suplico á $U$ se digne poner esto en conocimiento de la Junta $[\ldots]^{26}$

Una curiosa referencia según la cual la posibilidad de aplicar los castigos adecuados sería más importante que la edad del niño.

\section{Asistir y desistir de la escuela}

Una de las características regionales del valle de Toluca estuvo dada por la diversidad de actividades económicas que se compartían en un acotado radio geográfico. El mundo comercial se articulaba con la producción agraria y lacustre. Y ello se puede ser advertido a partir de los ritmos de concurrencia a las escuelas.

Uno de los informes elevado a la junta de instrucción pública de Ocoyoacac, por ejemplo, refería el panorama que se reconocía tras una visita a distintos establecimientos:

habiendo pasado a la escuela del Barrio de Cholula, en ella encontraron al Señor Preceptor con una regular concurrencia de niños; $y$ adelantos en sus respectivos ramos; y que la del Pueblo de Tultepec, aunque estaba asistida del Preceptor, no había niños por que aquel vecindario está actualmente ocupado en levantar su cosecha, de que está entendida la respetable Junta. ${ }^{27}$

En otro establecimiento, radicado en el casco urbano de la ciudad de Toluca, la perspectiva ofrecida por el preceptor Remigio Camacho acerca de la asistencia de los alumnos, señalaba con pesar: "Si uno mismo faltara siempre, sería malo; pero solo ellos serían los que se atrasaban; mas no sucede así, sino que se alternan $[\ldots] "$. Con el propósito de enmendar dichas inasistencias, así como con el afán

26 Expediente 8, vol. 1, Archivo Histórico Municipal de San Antonio la Isla (AHMSAI).

27 Expediente 11, vol. 1, serie Educación, Archivo Histórico Municipal de Ocoyoacac (AHMO). 
de limitar su responsabilidad, periódicamente le informaba al presidente de la junta acerca del asunto y este habría dado órdenes al auxiliar del barrio para obligar a los padres "a que remitan a sus hijos y no falten". Pero continuaban ausentándose. Cuando el maestro insistió reclamándole al auxiliar al respecto, este le contestó que no sabía dónde vivían algunos de los niños y sus padres, "o que ya ha reclamado pero que no hacen caso" 28 .

$\mathrm{Si}$ los calendarios y las fechas en que debían concurrir los alumnos pueden ser reconstruidos - no sin dificultad - , menos sencillo resulta conocer los ritmos con que dicha asistencia efectivamente se desarrolló. Atender a sus vaivenes permite referir a las condiciones sociales y económicas de los concurrentes, un aspecto clave en la caracterización de estas instituciones y una arista sugerente para el propósito de este análisis.

Para caracterizar el asunto, resulta ilustrativo un recurrente sustantivo empleado en distintos oficios. En numerosos listados tienen una presencia significativa los faltantes. Incluso hay casos en que su visibilidad supera a la de los que sí concurrían. Así, por ejemplo, un preceptor de San Antonio la Isla en 1859 remitió al ayuntamiento una lista con los alumnos que habían desistido de sus clases. Solicitó que la autoridad del ayuntamiento

pusiera el remedio oportuno a estas faltas; mas como las muchas ocupaciones de US no le habrán permitido dedicarse esclusivamente a este negocio, la impunidad ha animado a los faltistas y a los padres omisos; pues ni la tercera parte de los niños que antes venían vienen hoy a la enseñanza. ${ }^{29}$

La impunidad de los faltistas... tal propensión también parece haber atormentado al preceptor Felipe M. Gutiérrez en Capulhuac. A lo largo del año 1858 reiteró el tema en distintos oficios dirigidos al ayuntamiento ${ }^{30}$. Al iniciar el año 1859, la lógica con la que informó el asunto cobró un matiz sugerente, y apuntó:

Sin embargo las listas que le he remitido a Us. de los que frecuentemente faltan a la asistencia diaria, hoy por ser tan notable esta falta, no espero dar la lista hasta los ocho días según hemos convenido y para que vea Us. que no depende de mí esta falta, sino de la morosidad de los padres de los niños y de que algunos de estos los tiene aquellos destinados u ocupados en sus mismos intereses, y otros por enfermedad. ${ }^{31}$

Para el mes de julio, Gutiérrez no advertía cambios que mejoraran el panorama:

28 Expediente 10, caja 2, sección 1, Archivo Histórico Municipal de Toluca (AHMT).

29 Expediente 8, vol. 1, Archivo Histórico Municipal de San Antonio la Isla (AHMSAI).

30 Expediente sin número, sección Educación, fondo Educación, Archivo Histórico Municipal de Capulhuac (AHMC).

31 Ibid. 
Eran las tres y media y no habían concurrido al establecimiento mas que cinco niños y viendo esto pasé a la casa de Us. para ver que disponía sobre el particular; mas no abiendo encontradolo me volví al establecimiento y ahora que son las cuatro pasé lista y solo diez niños son los que hay, por cuya razón les tomé su lección y los mandé para su casa. Esto parece juego de niños, pues el que quiere venir viene y el que no nó y á la hora que quiere venir; sin embargo de los castigos que les impongo; pero todo esto depende de las ningunas disposiciones o si se dan no se cumplen, para que los padres de familia tengan cuidado de mandar con puntualidad a sus hijos, y estando persuadido de esto y de que así se pierde el tiempo y mi honor, dispuse cerrar el establecimiento y dar el aviso que doy a Us. para su inteligencia y fines consiguientes. ${ }^{32}$

¿Qué hacer, entonces, frente a las sostenidas inasistencias? Tras una de las visitas de los miembros de la junta de instrucción pública a la escuela de Almoloya, sus miembros consignaron las sanciones que aplicaron sobre los ausentes: "en el acto mismo se mandaron traer a 4 niños que faltaron y careciendo de proporcion sus padres fueron remitidos por el Sr. Presidente a 4 días de arresto y notificados que si seguían observando esta conducta serían castigados con arreglo a la ley"33. Esta fue una reacción inusual y poco frecuente, pero sirve para mostrar los límites a los cuales podría alcanzar la sanción.

Hubo otras experiencias en las que la concurrencia fue más regular, pero aludir a las faltas - incluso de los días sábado- constituyó una recurrencia de parte de los maestros. Así lo hizo Marcelo Méndez, quien fue preceptor de San Sebastián, en Metepec $^{34}$. Escribió una carta a la junta en la que observaba su disconformidad con las frecuentes ausencias de los niños. Indicó:

No siéndome posible impedir la falta casi total de los niños en los dias destinados al estudio de la doctrina cristiana, que son los sabados, acaso por ser en los que los mas de ellos tienen que despojarse de sus vestidos, y por consiguiente no ocurrir a la escuela, para asearse.

Parecería que Méndez fue un voluntarioso entusiasta. Tras lo indicado solicitó permiso para modificar el horario de las clases en los días sábados. Sugería dictarlas entre las cinco y media y las nueve de la mañana, con ello, aseguró, quizás lograba que algunos niños concurriesen a la vez que tendrían "tiempo suficiente durante el día para asearse". Indirectamente, la queja de Méndez sirve para considerar la regular asistencia de estos jóvenes en los restantes días de la semana. Así, había escuelas en que los alumnos tenían un comportamiento ajustado a lo anhelado por los maestros. Según expresaba el ya referido Camacho, él había puesto en marcha un establecimiento en el barrio de San Bernardino en la ciudad de Toluca. Cuando cambió de escuela, fue seguido por 54 alumnos que, aunque residían más alejados de la nueva locación, se trasladaban diariamente:

32 Ibid.

33 Expediente sin número, caja 19, Archivo Histórico Municipal de Almoloya de Juárez (AHMAJ).

34 Expediente 31, fondo Educación, Archivo Histórico Municipal de Metepec (AHMM). 
y da gusto verlos que a las 7 o 7 y media de la mañana se me presentan todos, sin faltarme uno, sino es por una razón, y por causa bien justificada. Todo lo que espero, se sirva U manifestar a la Junta de Instrucción Primaria, recomendando a los Padres de estos últimos, por tan decidido empeño en la educación de sus hijos, y para que se digne tomar cuantas medidas sean necesarias; $y$ sean de su resorte $[\ldots]^{35}$

El empadronamiento - visto con aversión por los pobladores ya que solía estrecharse a las levas o a propósitos fiscales - era una de las formas que tendrían las autoridades y los maestros para visar la periódica concurrencia. El preceptor de Capulhuac, F. Becerril, así lo manifestó en 1861 al presidente del ayuntamiento:

Este establecimiento ve con dolor que muchos de los niños que deben concurrir no lo verifican acaso por el abandono de sus padres y el desprecio con que ven la educación de ellos. Y como esta morocidad es bastante fácil de remediarse por esa Ilustre Junta, ocurro a US. con este objeto, sin atreverme a insinuarle los medios que debe valerse para la corrección de estas faltas en dichos padres de familias, pues los sabe muy bien; solo agregaré, que hace algunos días que pedí a las autoridades pasadas la formación del padrón de todos los niños de esta Población desde seis hasta quinces años de edad, y que este se me entregara para que yo formara la lista general y diera cuenta semanariamente a ese Juzgado con las faltas de los alumnos, pero no se me concedió $[\ldots]$. $^{36}$

Unos meses después Becerril volvió sobre el tema. Indicó que ya había solicitado en dos oportunidades el mencionado padrón, y le reiteraba el tema al presidente del ayuntamiento por tercera vez $z^{37}$.

Si las pautas diarias de asistencia eran poco respetadas, el horario de las clases lo fue menos. Según lo prescripto en 1840, las clases regulares debían desenvolverse cuatro horas en la mañana y dos horas por la tarde ${ }^{38}$. Pero más allá de lo prescripto, los usos de los establecimientos respondían a lógicas y usos locales. El preceptor Salazar de Capulhuac tuvo una discusión con el presidente de la junta de instrucción pública de Capulhuac sobre el tema. El vecino señaló que no era usual que la escuela se cerrara hacia las cinco de la tarde, "que era costumbre en este pueblo que la salida fuera a la metida del sol o cerca de ella". Esto no fue aceptado por el maestro y acordó en finalizar las actividades hacia las cinco y media. La negociación no terminó allí. Unos días después, los miembros de la junta de instrucción pública le solicitaron a Salazar que dictara clases

35 Expediente 16, caja 2, sección 1, ramo 10, Archivo Histórico Municipal de Toluca (AHMT).

36 Expediente sin número, sección Educación, fondo Educación, Archivo Histórico Municipal de Capulhuac (AHMC).

37 El maestro justificó su empeño con un argumento que vale la pena citar: "Y siendo este ramo [la educación] uno de los primeros, y del que dimana nada menos que la felicidad de todos los ciudadanos y de la Nación entera, creo debe ser por lo mismo el mejor atendido, como en lo sucesivo espero lograr". Ibíd.

38 “Artículo 9, 1840, Ordenanzas de escuelas de primeras letras", en Colección de Decretos del Congreso del Estado de México, $1824-1910$. comps. Mario Téllez G. y Hiram Piña L. (Estado de México: Universidad Autónoma del Estado de México - El Colegio Mexiquense, 2000). No deja de ser curioso que en los reglamentos previos de la zona no hubiera otras referencias acerca del tema. 
también los días sábados, lo cual fue aceptado por el preceptor bajo la condición de finalizar sus tareas semanales a las cinco. Y hubo acuerdo ${ }^{39}$.

El preceptor Camilo Andrade, en 1842, respondía a las críticas que se le habían efectuado por su desatención al establecimiento. En respuesta a lo observado señaló que nunca había faltado - incluso afirmó que dictaba más horas que las prescriptas - ; ahora bien, lo que sí eventualmente podría haber sucedido era que "algunos niños llegan a la escuela antes que nosotros, es porque sucede que a esa hora salimos a tomar nuestro alimento" ${ }^{\prime 0}$. Trece años después, en 1855, Andrade continuaba en el mismo establecimiento y entonces detallaba sus horarios con mayor precisión. Iniciaba sus clases con el alba y estaba al frente del aula unas nueve horas y media. Además, dedicaba media hora al mediodía y una hora al fin de los trabajos para el dictado de su cátedra de gramática castellana (solo a algunos niños). En total tenía inscriptos ciento cuarenta alumnos, de los cuales cotidianamente asistían entre ochenta y cien ${ }^{41}$.

El regular dictado era clave para la afirmación de los aprendizajes. Si distintos sectores sociales criticaban a los maestros por la lentitud en la alfabetización de los alumnos, muchos preceptores alegaron que las inasistencias constituían un factor determinante en tal falta de progreso.

Benigno Bovadilla fue un preceptor con una sugerente pluma. Los primeros meses en que se desempeñó, hacia 1840, en Ocoyoacac, expresó: "iba yo consiguiéndo algunos adelantos por el cumplimiento y la exactitud que se observaba", mas luego la asistencia de los niños mermó sensiblemente ${ }^{42}$. Y detallaba que desde entonces: "no hé conseguido reunir diariamente treinta jóvenes capaces de la educación; aunque yo por mi parte he puesto todos los esfuerzos necesarios para dar cumplimiento a mi destino". Culpaba a los padres por el abandono y la lastimosa situación en que dejaban a sus hijos. Estos "no son amantes de educar a sus hijos de por sí, sino es por reclamos judiciales". Y apelaba a la junta de instrucción pública para que ella "ponga toda su energía en hacer que haiga niños en el establecimiento; porque de lo contrario a mas de perder el tiempo los jóvenes, yo pierdo el concepto con no presentar un certamen regular". Aquí se trasluce una referencia que sería importante en la reputación y la buena consideración de las actividades escolares: el desarrollo de exámenes públicos. Estos constituían una puesta en escena en la que alumnos, maestros, miembros de las juntas, padres, ponían en juego distintos sentidos - políticos, sociales - a través de la evaluación de los contenidos memorizados o aprendidos por los escolares $^{43}$.

En Capulhuac, el preceptor García fue requerido por los miembros de la municipalidad a presentar sus alumnos a examen. En respuesta el maestro envió

\footnotetext{
39 Expediente sin número, sección Educación, fondo Educación, Archivo Histórico Municipal de Capulhuac (AHMC).

40 Expediente 17, fondo Educación, Archivo Histórico Municipal de Metepec (AHMM).

41 Expediente 41, caja 2, fondo Educación, sección Educación, Archivo Histórico Municipal de Metepec (AHMM).

42 Expediente 5, serie Educación, fondo Educación, Archivo Histórico Municipal de Ocoyoacac (AHMO).

43 Bustamante Vismara, Escuelas en tiempos de cambio; Eugenia Roldán Vera, "La escuela mexicana decimonónica como iniciación ceremonial a la ciudadanía: normas, catecismos y exámenes públicos”, Bordón. Revista de orientación pedagógica vol. 62, n. ${ }^{\circ} 2$ (2010).
} 
una carta solicitando que sus alumnos fueran eximidos de dicha presentación ${ }^{44}$. Daba cuenta de los pocos meses que llevaba al frente del establecimiento. Había iniciado sus labores en septiembre de 1859 con un buen número de alumnos, pero a las pocas semanas varios de estos dejaron de concurrir "pues que la generalidad de la prole ocupose en la faena local de familia que constituyen los trabajos de la Cosecha del maiz". Tras la finalización de estas actividades, los jóvenes retornaron a la escuela hacia el mes de enero de 1860, cuando nuevamente se vio truncada la actividad escolar por la preparación para el advenimiento de una misión religiosa. Los propios padres de familia habrían solicitado que durante esas semanas se diera preferencia al adoctrinamiento religioso. $Y$ en estos trabajos estuvo hasta pocos días antes, cuando en marzo recibió el pedido del ayuntamiento para presentar alumnos a un certamen público. García solicitaba postergar dicha presentación; con un "respiro" de dos o tres meses podría presentarlos: "acaso con el satisfactorio resultado, que, con el favor divino, hé visto otros en mi dilatada carrera de Preceptor, y que han constituido en parte el mérito para la continuación de esta" ${ }^{45}$. Las frecuentes inasistencias - ya se ha mencionado - impactaban en el crédito de un maestro. Julio Camacho, preceptor en San Felipe, Metepec, hacia 1854, aludía con tristeza a la cantidad de faltas que tenían sus alumnos: "he visto con sentimiento destruida mi esperanza" 46 . Solo lo consolaba la posibilidad de servir al pueblo "en una época más feliz", mas por lo pronto dejaba su cargo en manos de otro colega. También en Metepec, el ya mencionado Andrade, describía las inasistencias con pesar:

Lleno de sentimiento estoy notando las repetidas faltas a la escuela de la mayor parte de los niños. Tristes son las consecuencias que resultan de ellas, pues los trabajos emprendidos que prometen las esperanzas más lisonjeras se hacen inútiles y penosísimas

El año próximo pasado abrí el curso de gramática castellana con 25 niños y el presente no he podido conseguir que concluyan la primera parte diez a lo menos porque las faltas de unos impiden el adelanto de otros, y las de estos a su vez, el adelanto de aquellos: unos y otros recíprocamente se perjudican, pues que siempre se está recordando lo aprendido, que con la mayor facilidad se olvida, siempre se practica una sola cosa, y pocas veces se da paso adelante. Acaso se me propondrá el que solo me dedique a los que ocurren con constancia, separando sucesivamente a los que vayan faltando: mas de esto solo resultará el que uno o dos niños sean los que adelanten, lo que no puede conformarme jamás, por razones que ni necesario me parece exponer. Esto que hago presente respecto al ramo de gramática castellana, se extiende igualmente al de ortografía, aritmética y las demás. ${ }^{47}$

44 Expediente sin número, sección Educación, fondo Educación, Archivo Histórico Municipal de Capulhuac (AHMC).

45 Ibid.

46 Expediente 39, caja 2, fondo Educación, Archivo Histórico Municipal de Metepec (AHMM).

47 Expediente 30, caja 1, fondo Educación, Archivo Histórico Municipal de Metepec (AHMM). 
La extensión de la cita es ameritada por la riqueza de la descripción. De hecho, no terminan allí los detalles ofrecidos por este maestro, para quien las consecuencias de aquellas inasistencias no solo afectaban al desempeño escolar o a la actuación de los jóvenes en los certámenes escolares, repercutían en ondas consecuencias sociales:

No para aquí el perjuicio que ocasionan las faltas continuas de los niños. Hé obser-
vado que engolosinados, si puedo explicarme así, con el ocio a que por lo regular
se hayan entregados cuando están fuera de la escuela, les es tan difícil después a
muchos el habituarse a los trabajos peculiares de ella, que de ahí proviene, a mi
entender, aquella aversión que con frecuencia se les advierte al volver a ellos, y que
muchas ocasiones es causa de que contraigan peores costumbres que gradualmente
los conducen a los vicios. Aún aquellos que con tesón e interés se dedicaban al
cumplimiento de sus deberes escolares, se les vé no raras veces de desmayar enton-
ces. ${ }^{48}$

\section{CONCLUSIONES}

En este artículo se presentan rastros de algunas experiencias de niños en un contexto particular. No solo se atiende a una región y un período acotado, sino que la mirada se posa en niños que pasaron por escuelas ligadas a los ayuntamientos. El conjunto permite reconocer algunas de sus vivencias, pautas de relación con maestros, padres y autoridades municipales. Y lo sucedido en el valle de Toluca no parece haber sido excepcional en el desarrollo social de Hispanoamérica.

Una privilegiada referencia ha estado posada sobre aspectos relacionados a la asistencia y a los castigos. Escolares varones han estado en el centro de las descripciones. Esto no ha sido motivado por un interés particular en estos temas, sino por el sesgo con que los maestros o autoridades atendían a los alumnos. La limitación a estos temas supone dejar sin respuesta un amplio espectro de asuntos: ¿dónde están las alumnas?, ¿qué pensaban estos niños acerca de sus maestros o maestras?, ¿qué miradas tenían los padres y las madres sobre la necesidad de una regular asistencia a la escuela? Sin dudas, los expedientes trabajados están limitados por numerosos sesgos para tratar en toda su riqueza el problema, pero hay elementos sugerentes que a través de ellos pueden reconocerse. Incluso aquí se ha enfatizado que, sin los aportes recuperados desde archivos históricos municipales, el universo social de los alumnos permanecería aún menos visible. Dicho de otra manera, desde la información recogida en repositorios más generales, las posibilidades de reconocer a este sector social serían aún más acotadas. 
Son imágenes acerca de escolares que no están organizadas ni por la visión moderna que idealizó la infancia, ni por el sistema escolar que se articuló a fines del siglo XIX. La propuesta dialoga con el afán por recuperar prácticas ligadas a instituciones y estrategias para educar y gobernar a las infancias.

El frágil papel sobre el que escribían estos niños - cuando lograban avanzar sobre el aprendizaje de la escritura -, la escasez de memorias o narraciones que den cuenta de tales experiencias y sus papeles sociales no han dejado demasiados testimonios sobre sus trayectorias, por lo que los registros que sobre ellos pueden encontrarse son un haz de referencias. Al articularlas y ponerlas en relación se busca darle inteligibilidad a procesos locales de apropiación de la educación con relación a estos elusivos alumnos.

\section{FUENTES}

Archivo General de la Nación, México, D.F.

Archivo Histórico del Estado de México, Toluca.

Archivo Histórico Municipal de Almoloya de Juárez.

Archivo Histórico Municipal de Calimaya.

Archivo Histórico Municipal de Capulhuac.

Archivo Histórico Municipal de Metepec.

Archivo Histórico Municipal de Ocoyoacac.

Archivo Histórico Municipal de San Antonio la Isla.

Archivo Histórico Municipal de Tenango del Valle.

Archivo Histórico Municipal de Toluca.

Archivo Histórico Municipal de Zinacantepec.

Biblioteca del Congreso del Estado de México “José María Luis Mora”, Toluca.

Colección de Decretos del Congreso del Estado de México, 1824-1910. Compiladores Mario Téllez G. y Hiram Piña L. Estado de México: Universidad Autónoma del Estado de México - El Colegio Mexiquense, 2000.

Manuel Dublán, Mario Téllez G., y José López Fontes. La legislación mexicana de Manuel Dublán y José María Lozano [disco compacto, vol. 1]. México, D.F. - Toluca: Suprema Corte de Justicia de la Nación - El Colegio de México - Escuela Libre de Derecho - Tribunal Superior de Justicia del Estado de México, 2004.

\section{REFERENCIAS}

Arredondo López, María Adelina. En la senda de la modernidad: un siglo de educación en Chihuahua, 1767-1867. Zamora, Michoacán, México: El Colegio de Michoacán, 2011.

Bazant de Saldaña, Mílada. En busca de la modernidad: procesos educativos en el Estado de México, 18731912. Zinacantepec - Zamora, México: El Colegio Mexiquense - El Colegio de Michoacán, 2002.

Bustamante Vismara, José. Escuelas en tiempos de cambio: política, maestros y finanzas en el valle de Toluca durante la primera mitad del siglo XIX. México, D.F.: El Colegio de México, Centro de Estudios Históricos, 2014.

Bustamante Vismara, José. "Un proceso de reorganización territorial advertido desde las escuelas elementales: el valle de Toluca entre fines del siglo XVIII y principios del siglo XIX". Tzintzun. Revista de Estudios Históricos n. ${ }^{\circ} 61$ (2015): 245-267.

Civera, Alicia. "Alcances y retos de la historiografía sobre la escuela de los campos en América Latina (siglos XIX y XX)". Cuadernos de Historia n. 34 (2011): 7-29. 
Escalante Fernández, Carlos. Mazahuas, campesinos y maestros. Prácticas de escritura, tierras y escuelas en la historia de Jacotitlán, Estado de México (1879-1940). Zinacantepec, México: El Colegio Mexiquense, 2014.

Rincón Verdugo, Cecilia. "Historiografía sobre las significaciones imaginarias de infancia en la cultura de Occidente". Revista Historia de la Educación Latinoamericana 20, n. 31 (2018): 25-46.

Rodríguez Jiménez, Pablo y María Emma Mannarelli, coordinadores. Historia de la infancia en América Latina. Bogotá: Universidad Externado de Colombia, 2007.

Roldán Vera, Eugenia. “La escuela mexicana decimonónica como iniciación ceremonial a la ciudadanía: normas, catecismos y exámenes públicos". Bordón. Revista de orientación pedagógica 62, n. ${ }^{\circ} 2$ (2010): 67-79.

Roldán Vera, Eugenia. The British Book Trade and Spanish American Independence: Education and Knowledge Transmission in Transcontinental Perspective. Aldershot, Hants, England: Ashgate, 2003.

Sosenski, Susana, y Elena Jackson Albarrán, coordinadoras. Nuevas miradas a la historia de la infancia en América Latina: entre prácticas y representaciones. México, D.F.; Universidad Nacional Autónoma de México - Instituto de Investigaciones Históricas, 2012.

Staples, Anne. "Recent Trends in the Historiography of Mexican Education". Paedagogica Historica 36, n. 3 (2000): 955-976.

Staples, Anne. Recuento de una batalla inconclusa: la educación mexicana de Iturbide a Juárez. México, D.F. : El Colegio de México, 2005.

Tanck de Estrada, Dorothy. Pueblos de indios y educación en el México colonial, 1750-1821. México, D.F.: El Colegio de México - Centro de Estudios Históricos, 1999.

Cómo citar:

Bustamante Vismara, José. El elusivo paso por las escuelas: alumnos en el Estado de México a mediados del siglo XIX. Revista Historia de la

Educación Latinoamericana. vol. 22 No. 34 (2020): 201-218

DOI: https://doi.org/10.19053/01227238.10896

(c) (i) (9) Esta obra está bajo una licencia Creative Commons. Reconocimiento-No Comercial-Sin Obra Derivada 2.5 Colombia. 